\title{
A Case of Osteoporosis with Bilateral Defects in the Mandibular Processes
}

\author{
Masahiko Miyake', Yasuyuki Oda ${ }^{1}$, Shinkichi Iwanari ${ }^{1}$, Itsuro Kudo ${ }^{1}$, Takayoshi Igarashi², \\ Kazuya Honda ${ }^{3}$, Koji Shinoda ${ }^{3}$ and Eikou Sairenji ${ }^{4}$
}

(Received 22 November 1994 and accepted 8 April 1995)

\begin{abstract}
Key words: osteoporosis, bilateral defects in the mandibular processes, microdensitometry (MD) method
\end{abstract}

\begin{abstract}
We carried out a detailed total body examination of a 62-year-old woman with osteoporosis who had bilateral defects in the mandibular processes. It was inferred that the defects in both articular heads were caused by resorption of small bone fragments following fracture. The quantity of bone salt was determined by microdensitometry, and a diagnosis of osteoporosis was then established. An improved bite was obtained by treatment consisting of tooth extraction and the preparation of partial dentures.
\end{abstract}

\section{Introduction}

The number of patients with osteoporosis is increasing in the current aging society, constituting an important social problem ${ }^{[1-3]}$. Osteoporosis is defined as a condition in which the bone density of osseous tissue is decreased without any changes in the morphology of the bone ${ }^{[4]}$. Previous studies of oral biology have described osteoporosis in relation to the growth of the jaw bone or the condition of the alveolar ridge $^{[5,6]}$. However, to our knowledge, there have been few clinical cases reported in the literature. This report presents an outline of a recent case of osteoporosis with bilateral defects in the mandibular processes, and describes the results of bone density measurement by microdensitometry (MD) ${ }^{[7] \text { in the }}$ patient.

\section{Case Report}

The patient was a 62-year-old woman who visited the Department of Oral and Maxillofacial Surgery at Nihon University School of Dentistry Hospital on May 12, 1989, because of malocclusion. Her family history was not contributory. She had had appendicitis and nephritis at 12 years of age and cholecystitis at 26 years. Menopause had occurred at 42 years, and thereafter the patient had decreased in stature, and was diagnosed as having osteoporosis when she suffered a compression fracture of the thoracic spine at the age of 43. She underwent surgery for hernia of intervertebral at the age of 45. In February 1988, she suffered pain in the right temporomandibular disk joint when she was eating beans, and this was followed by trismus lasting for about 3 days. At about this time, spontaneous pain also occurred in the left temporomandibular joint and persisted for about 6 months. Since she showed regression of the mental region and open bite of the lower anterior teeth during this period, she visited a dental clinic and was referred to our department. She was rather small, $34 \mathrm{~kg}$ in weight and $126.5 \mathrm{~cm}$ in height, and had spinal curvature. Her face was symmetrical, although there were some features of bird face (Fig.1). No regional lymph nodes were palpable. The degree of mouth opening was $40 \mathrm{~mm}$, and the transverse movement was $10 \mathrm{~mm}$ to the right and $12 \mathrm{~mm}$ to the left. Mandibular movement was linear on a sirognathogram (Figs. 2-A. B ).

三宅正彦、小田泰之、岩成進吉、工藤逸郎、五十嵐孝義、本田和也、篠田宏司、西蓮寺永康

1 Department of Oral and Maxillofacial Surgery, Nihon University School of Dentistry

2 Department of Crown and Bridge Prosthodontics, Nihon University School of Dentistry

3 Department of Radiology, Nihon University School of Dentistry

4 University Research Center, Nihon University

To whom all correspondence should be addressed: Dr. Masahiko Miyake, Department of Oral and Maxillofacial Surgery, Nihon University School of Dentistry, 1-8-13 Kanda-Surugadai, Chiyoda-ku, Tokyo 101 JAPAN 
In the oral cavity, there was $\frac{64-7}{3-3}-7$, with an opening of about $3 \mathrm{~mm}$ at $\frac{1}{1}$ and the only contact occurred at $\mid \frac{7}{8}$ (Fig. 3). Orthopantomography and other radiographic procedures revealed a defect at the origin of the mandibular process on both sides (Figs. 4-A. B, 5-A. B, and 6).

It was apparent in a frontal view of the thoracic region (Fig. 7-A) that the thoracic cavity was deformed by the curvature of the spine. In a lateral view of the same region (Fig. 7-B), the bones were generally osteoporotic, and compression fracture caused flattening and wedging of the vertebral body of the 8th and 11th thoracic vertebrae and 2nd and 4th lumbar vertebrae, some intervertebral discs being deformed. In the abdominal region, stones were found in the right renal pelvis and at the left ureterovesical junction (Fig.8). Examination of other bones revealed fatigue fracture of the left cuneiform bone.

Clinical laboratory data are shown in Table 1. Although there were some abnormalities, the levels of Al-P, Na, K, Cl, Ca, P, Mg, BUN, GOT and GPT were normal.

\section{Assessment of bone atrophy by MD}

Various methods have been devised for diagnosing osteoporosis. In the present study, we measured the bone density according to a microdensitometric procedure employed by Inoue et al. ${ }^{[7]}$ for determining bone density in patients with metabolic bone disease. First, radiograms of the dorsal part of the hand were obtained, using an aluminum step wedge, at a distance of $1 \mathrm{~mm}$ using conditions of $50 \mathrm{kV}, 100 \mathrm{~mA}$ and $0.05 \mathrm{~s}$. Second, the radiograms were subjected to microdensitometry to collect data at the middle of the second metacarpal bone, and patterns of shadows of varying intensity were analyzed for the items shown in Fig. 9.

The results are shown in Table 2. A comparison of our data and those reported by Inoue et al ${ }^{[7]}$ revealed that the values of D, MIC, GSmax, and $\Sigma$ GS/D obtained in our patient were lower ( $\pm 5 \%$ or more), and the $\mathrm{d}$ value slightly higher, than the normal values for persons in their $60 \mathrm{~s}$. The densitometer pattern was close to type $\mathrm{C}$. On the basis of these findings, a diagnosis of osteoporosis was established.

The clinical diagnosis of the patient's condition was postomenopausal osteoporosis with bilateral defects in the mandibular processes.

After the first examination, the patient underwent assessment of bone atrophy by MD and a detailed total body examination. Since the patient showed sufficient mouth opening and had no pain during mandibular movement, upper and lower partial dentures were fitted after tooth extraction $\left(\frac{6}{8}\right)$. The use of the dentures provided a favorable state of bite and enabled satisfactory oral feeding, with which the patient was satisfied (Figs. 10-A. B).

\section{Discussion}

Osteoporosis is defined as a condition in which the bone density of osseous tissue is decreased while there are no changes in bone morphology $y^{[4]}$. Its occurrence is considered to be attributable to impairment of the relationship between bone resorption and addition. Patients with this disease are therefore very likely to suffer fracture due to slight injuries. In general, compression fracture of the spinal column is most frequent, and the most serious complication of this is femoral neck fracture in view of the fact that it produces a great obstacle to activities of daily living ${ }^{|2|}$. Although details remain unclear, the course of the disease in our patient suggests that pathological fracture might have occurred in the mandibular processes, followed by bone resorption.

Fracture in osteoporotic patients is generally treated by standard therapeutic procedures. However, they have thin and weak cortical bones, and the fracture line is not simple. Therefore, it is often difficult to maintain the proper position of the fractured part by external fixation alone, although reduction is possible. Moreover, bone union after fracture in these patients is slower than that in young patients, often causing prolongation of the treatment ${ }^{[4]}$. In our patient, we performed tooth extraction and prepared partial dentures, assuming that prosthetic treatment would achieve a favorable bite, since mandibular movement was nearly normal despite the presence of defects in the articular heads.

Osteoporosis has recently become a topic attracting much attention along with aging of our society ${ }^{[1-3]}$, 
and quantification of bone-salt has become common for determining atrophic changes in bone. Methods used for such quantification include MD, SAP, DPA and QCT. The method we used in the present study was MD, which has the advantage of simplicity, high utility and minimal patient burden.

Mandibular impairment associated with osteoporosis like that in our case has not been reported previously in the literature, suggesting its comparative rarity. We intend to continue follow-up observation of our patient.

\section{Conclusion}

We have recently experienced a case of bilateral defects in the mandibular processes found in a 62 year-old woman with osteoporosis. An outline of this case and the results of measurement of the bone density by microdensitometry are described .

\section{References}

[1] Shiraki, M.: Bone diseases, Jpn. J. Clin. Nutr., 74, 640-650, 1989 (in Japanese)

[ 2 ] Yamamoto, K.: Diagnosis and treatment of osteoporosis, Orthop. Surg., 41, 265-273, 1990 (in Japanese)

[ 3 ] Jeffcoat, K.M. and Chesnut III, H.C.: Systemic osteoporosis and oral bone loss, J.Am. Dent.Assoc., 124, 49-56, 1993.

[ 4 ] Mori, Y.: Bone resorption and osteoporosis, J. Osaka Odontol.Soc., 2, 59-75, 1983 (in Japanese)

[ 5 ] Shapiro, S., Bomberg, T.J., Benson, B.W. and Hamby, C.L.: Postmenopausal osteoporosis: dental patients at risk, Gerodontics, 1, 220-225, 1985.

[6] Iwanaga, N.: A radiological, light and electron microscopic study of the effect of active type vitamin D3 on experimental osteoporosis-Especially Change in the Mandibular Condyle at Growth Stage, $J$. Kyushu Dent. Soc., 43, 226-262, 1989 (in Japanese)

[ 7 ] Inoue, T., Sumi, Y.:A Radiological Measurements of Bone Density, Plastic Surgery MOOK., 34, $12-$ 35, 1984 (in Japanese). 


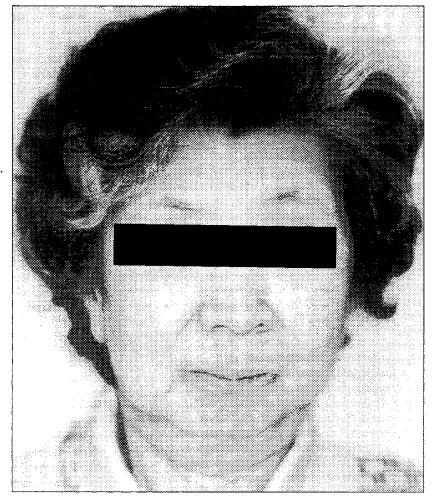

Fig.1 Frontal view of patient on initial presentation.

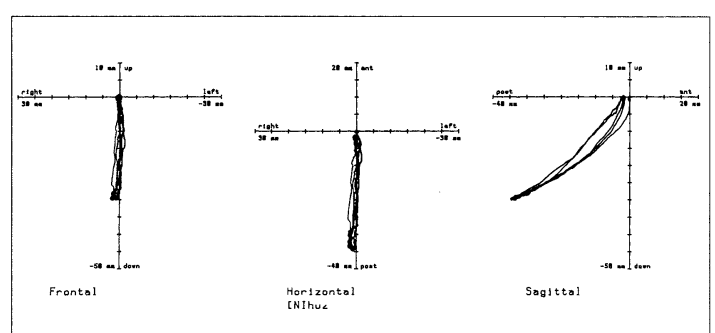

Fig. 2-A Sirognathograph (opening pathway)

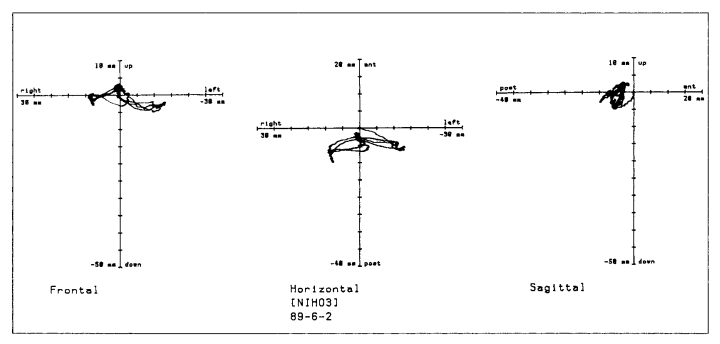

Fig. 2-B Sirognathograph (lateral pathway)

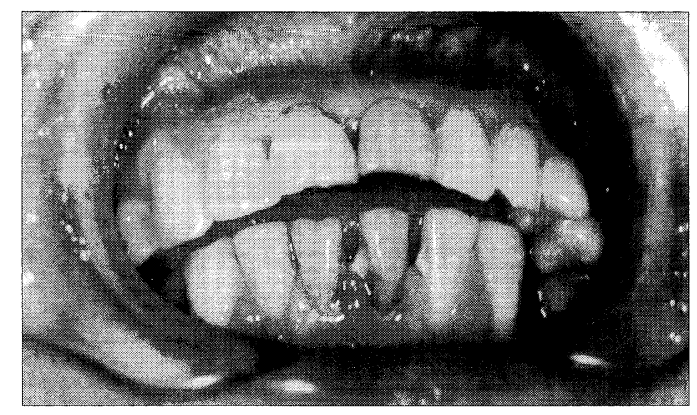

Fig. 3 Occulusion view on initial presentation

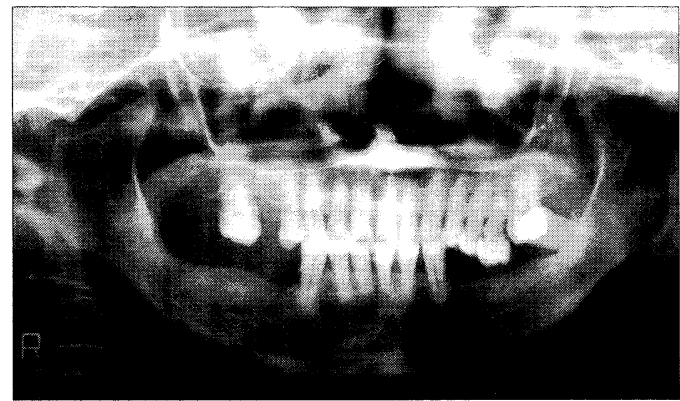

Fig. 4-A Orthopantomography on initial presentation (closed bite)

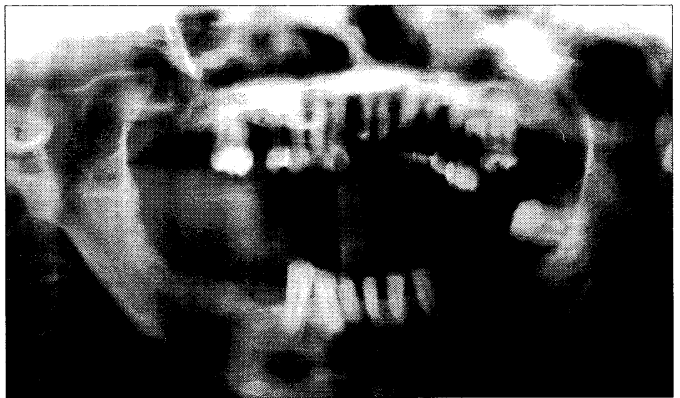

Fig. 4-B Orthopantomography on initial presentation (opened bite) 


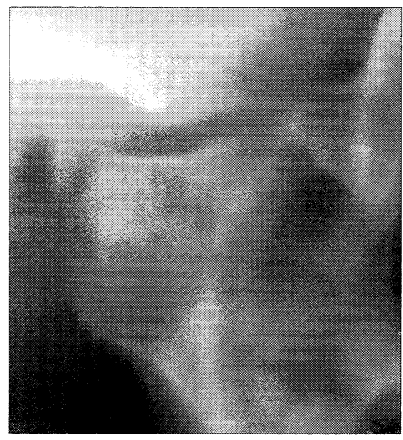

Fig. 5-A Tomography (right side)

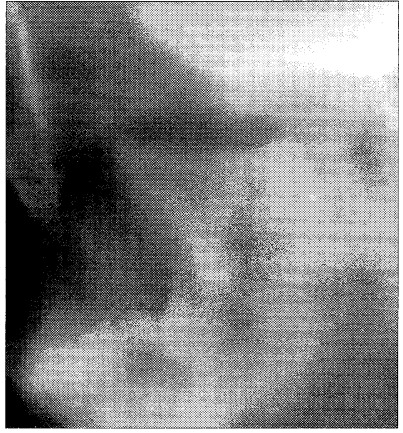

Fig. 5-B Tomography (left side)

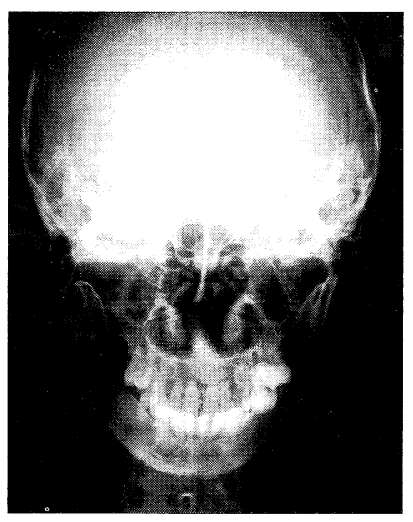

Fig. 6 Postero-anterior radiography on initial presentation

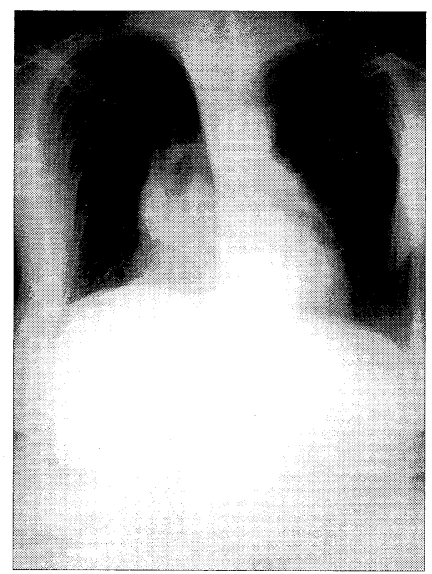

Fig.7-A Front radiograph view of the thoracic and abdominal region

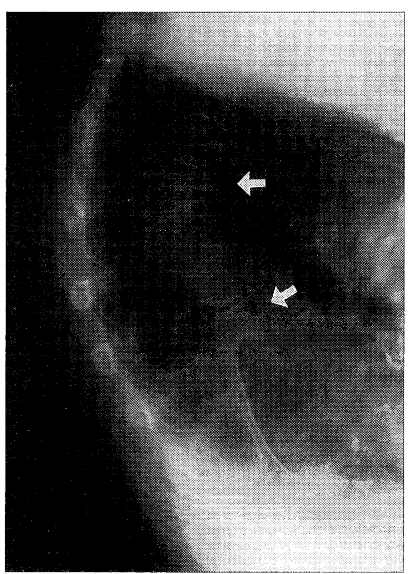

Fig.7-B Lateral radiograph view of the thoracic region 


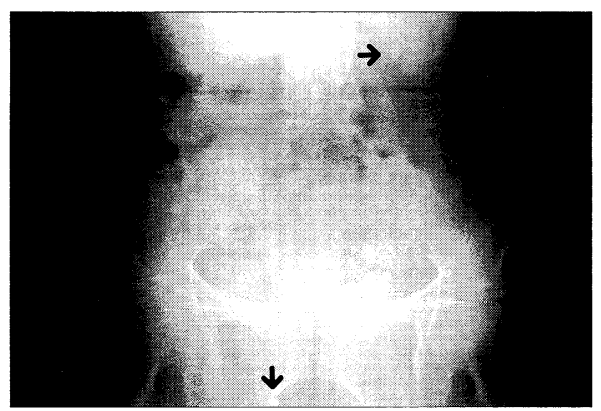

Fig. 8 Front radiograph view of the abdominal region showed a calculi (arrow)

Table 1 Clinical laboratory data

$\begin{array}{ll}\text { RBC } & 471 \times 10^{4} / \mathrm{mm}^{3} \\ \text { WBC } & 115 \times 10^{2} / \mathrm{mm}^{3} \\ \text { Hb } & 15.2 \mathrm{~g} / \mathrm{dl} \\ \text { Ht } & 46.4 \% \\ \text { Plat } & 28 \times 10^{4} / \mathrm{mm}^{3} \\ & \\ \text { ALP } & 9.1 \mathrm{KAU} \\ \text { GOT } & 32 \mathrm{KU} \\ \text { GPT } & 20 \mathrm{KU} \\ \text { LDH } & 345 \mathrm{~W} . \mathrm{U} \\ \text { LAP } & 205 \mathrm{GU} \\ \text { Ch-E } & 0.76 \triangle \mathrm{pH} \\ \text { TTT } & 58 \mathrm{U} \\ \text { ZTT } & 15.1 \mathrm{~K}-\mathrm{U} \\ \text { TP } & 16.2 \mathrm{mg} / \mathrm{dl} \\ \text { CREA } & 0.6 \mathrm{mg} / \mathrm{dl} \\ \text { Glu } & 83 \mathrm{mg} / \mathrm{dl} \\ \text { Tcho } & 333 \mathrm{mg} / \mathrm{dl} \\ \beta \text {-Lp } & 2.5 \mathrm{mg} / \mathrm{dl} \\ \text { T-Bill } & 0.4 \mathrm{mg} / \mathrm{dl} \\ \text { BT } & 2 \mathrm{~m} 00 \mathrm{~s} \\ \text { CT } & 8 \mathrm{~m} 30 \mathrm{~s} \\ \text { PTT } & 11.9 \mathrm{~s} \\ \text { APTT } & 13.2 \mathrm{~s} \\ \text { blood type } & 22.1 \mathrm{~s} \\ & 33.0 \mathrm{~s} \\ & \text { A }(+) \\ & \\ & \end{array}$

Electrolyte

$\begin{array}{lr}\mathrm{Na} & 143 \mathrm{mEq} / \mathrm{l} \\ \mathrm{K} & 4.20 \mathrm{mEq} / 1 \\ \mathrm{Cl} & 106 \mathrm{mEq} / 1 \\ \mathrm{IP} & 9.2 \mathrm{mg} / \mathrm{dl} \\ \mathrm{Mg} & 3.4 \mathrm{mg} / \mathrm{dl}\end{array}$

CRP

$(-)$

ASO

$(-)$

RA

$(-)$

LAP

Stab $\quad 1 \%$

Seg $\quad 56 \%$

Eos $\quad 1 \%$

Bas $2 \%$

Mono $\quad 5 \%$

Lymph $\quad 35 \%$

$\mathrm{A} / \mathrm{G} \quad 1.17$

A $\quad 54.0 \%$

$\alpha 1 \quad 4 \%$

$\alpha 2 \quad 9.8 \%$

$\beta \quad 13.2 \%$

$\gamma \quad 18.9 \%$

IS

HS-PTH $310 \mathrm{pg} / \mathrm{ml}$

Karsitonin 61 pg/ml 


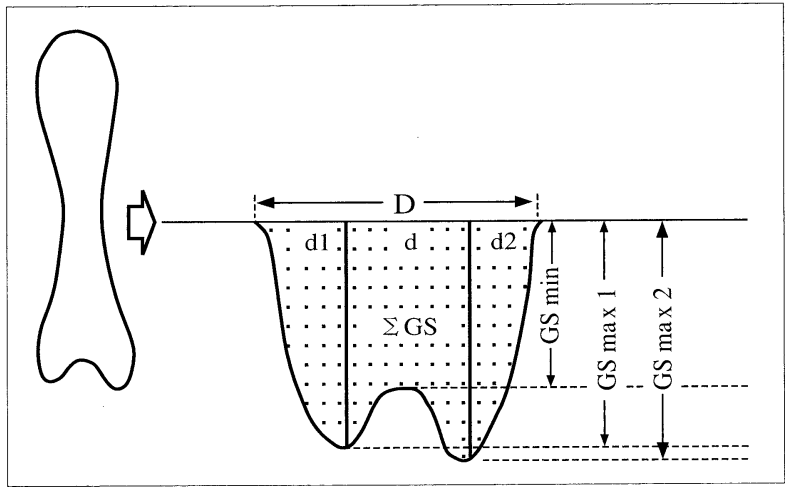

Fig. 9 Desitometer pattern of the second metacarpal bone

Items for analysis

1) $\mathrm{D}$ : bone width

2) $d$ : width of bone marrow

3) $\mathrm{MCI}(=(\mathrm{d}+\mathrm{d}) / \mathrm{D})$ : ratio of bone cortex

4) GSmin : image intensity at the center

5) GSmax $(=(G S+G S) / 2)$ : image intensity at bone cortex

6) $\Sigma$ GS/D : image intensity per bone width

7) densitometric pattern : bone pattern

Table 2 The Results of each Analysis

$\begin{array}{lcc}\text { Items for analysis } & \text { normal (in the 62s) } & \text { patient data } \\ \text { 1) } \mathrm{D} & 8.56 & 7.50 \\ \text { 2) } \mathrm{d} & 4.95 & 5.0 \\ \text { 3) } \mathrm{MCI} & 0.42 & 0.33 \\ \text { 4) GSmin } & 1.80 & 1.20 \\ \text { 5) GSmax } & 2.70 & 2.45 \\ \text { 6) } \Sigma \text { GS/D } & \text { approx. } 1.90 & 1.75\end{array}$

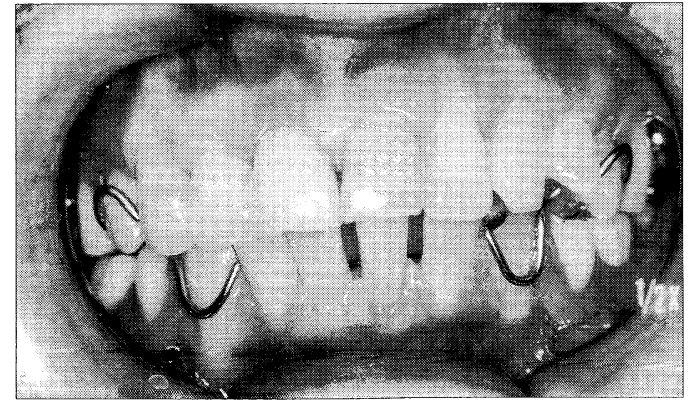

Fig.10-A Occulusion view on set partial denture after extraction

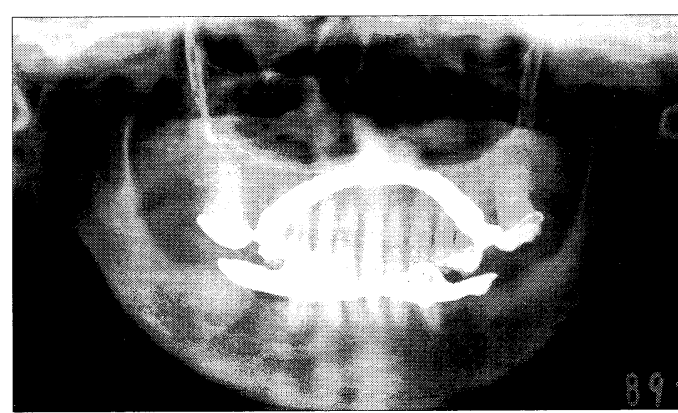

Fig.10-B Orthopantomography on set partial denture after extracton 